\title{
MONITORING THE DEFORMATION PROCESS OF ENGINEERING STRUCTURES USING BIM TECHNOLOGIES
}

\author{
A. Annenkov ${ }^{1}$ \\ ${ }^{1}$ Kyiv National University of Construction and Architecture, Ukraine - (geodez74@ gmail.com)
}

Commission V, WG V/7

KEY WORDS: BIM, Navisworks, Verity plugin, geotechnical monitoring, building structure

\begin{abstract}
:
This paper reports on the scientific approach to integrating the results of geodetic measurements into an integrated BIM system for geotechnical monitoring of building structures. The method is based on systematic monitoring of deformations with the determination of the influence of external factors, which makes it possible to process a significant amount of information obtained during the monitoring process and promptly process the information about the stress-strain state of the object in real-time.

New technology for assessing the technical condition of high-rise buildings is proposed. The core of this technology is an estimation of defects and deformations of structures using BIM during the building construction and operation.

Using the mathematical tools of BIM technology in geotechnical monitoring of engineering structures makes it possible to create a quantitative information model. The model comprises the results of geodetic measurements, measurements of climate loads, and measurements of geological deformations. As a result, a quantitative assessment of defects and damage during the construction and operation of high-rise buildings becomes possible.

BIM allows determining the risks of critical states occurrence of building structures, assessing the probability level of their occurrence, and predicting the degree of influence of these risks on the safe operation of the entire structure. Simultaneously, the BIM estimates the stress-strain state of a high-rise building based on the results of deformation monitoring. The considered approach is affordable to any measurements. The use of information technologies in the monitoring of engineering structures during construction and operation will make it possible to collect and accumulate significant statistical data related to the influence of specific external factors on the stress-strain state of the structure. Subsequent processing of this information will make it possible to identify and predict the dependence of defects and deformations of building structures on certain factors and clarify their weight values.
\end{abstract}

\section{INTRODUCTION}

With the development of technological progress, as well as digital technologies, it is relevant to discover the question of the possible application of this direction in matters of geodetic support of the construction process. Nowadays in the construction industry, BIM technologies take start to be actively used. BIM (Building Information Modeling) is the process of creating an integrated model of a future construction object, which includes all stages of the project life cycle starting from the site investigation stage to the demolition stage. BIM technology is the tool that allows increasing the efficiency of interaction among all the project participants. BIM is based on a 3D information model.

Today BIM technologies are implemented in all areas of engineering. Architects, engineers, designers, managers around the world master this technology and it is slightly moving from the category of luxury to the category of living standards. Particularly in Ukraine more and more design and construction organizations have completely switched to the use of BIM in their engineering activities. This kind of information technology significantly saves time and money at all stages of the life cycle of a building.

It is important to mention that this technology brings the greatest efficiency when it comes to an integrated approach while working with a construction object, when the information model covers all areas of the engineering object service. In this case, the more accurately the BIM model of an engineering structure is built at the initial stage, the more likely in future it will work without failures and errors in real time. This technology will reduce the number of errors in the process of construction and operation, incoordination in construction operations, it will increase the quality of monitoring of structural deformations and improve the quality of the relation customer-designer- builder.

Certainly, it is also important to mention the disadvantages of BIM. For example, the following ones: high cost of software products; long process of specialists retraining; insufficient regulatory framework (for Ukraine in particular); change of the general concept of the design process, which is sometimes psychologically difficult for engineers; development of new design practices, etc. But all these problems are of an indirect nature and over time they will disappear with the growth of the engineering revolution. All of these problems will be eventually replaced by the undeniable benefits of information modeling.

Having analyzed all the advantages and disadvantages, it is possible to state that the transition to BIM is a matter of time and this transition has long been taken and it has no return. The introduction of BIM technology is beneficial both for large corporations and for each participant in the engineering maintenance of the building separately. In the modern world, in which there is an importance about speed of completing the 
task, visibility of the model, efficiency of results and decisionmaking, BIM technology is an indispensable tool for any engineer involved in the design of an engineering structure. BIM-modeling allows not only presenting the work in a new, high-quality informational and visual form, but also creating a model that will be as close to reality as possible. Consequently, it will help avoid design errors and structural deformations during the design and further building operation.

The purpose of the study is to develop a methodology for monitoring deformation processes of engineering objects and for assessing the quality of construction operations using a set of BIM-technology tools when digitizing geodetic measurements.

\subsection{Research Problem}

The authors (Panfilova, Malkin, 2020) note that BIM technology can be used not only as a tool, but also as a process for organizing high-quality design project. He shows that the high-quality organization of the design process within different departments allows getting a high-quality project.

Participation in the development of design information management systems in the enterprise also plays an important role in increasing of competitiveness. In works (Aziz et al. 2016; Dinga et al. 2016; Jee Woong Parka et al. 2017; Zoua et al. 2017; Aziz et al. 2017), much attention is paid to the development and application of BIM-technology in the implementation of investment and construction projects, as well as the development of BIM-technology in alternative areas of everyday life.

The authors (Sigalov et al. 2017; Bradley et al. 2016; Wetzel et al. 2015; Kang et al. 2015) suggest to assess various risks. They (the authors) being at the design stage, already use a 3D model of a future project after creation an algorithm that enables to analyze new errors and to warn participants of a future project. It is worth mentioning that the use of BIM technology in construction process planning at the design stage makes it possible to assess most of the risks associated directly with production. Information technologies also enable to evaluate the typical processes of the entire project and to build clearer logistics for them.

In (Zhang et al. 2013), BIM technologies are viewed in the process of urban planning, when the use of these technologies can stimulate the development of a city cadastre.

Since BIM geodetic project is a product of exclusively computer and engineering field, the work with it will be carried out on the basis of modern software specialized complexes. As a software product for information modeling of geodetic monitoring of buildings and structures, we used the Revit platform from Autodesk. In order to implement the methodology for controlling the actual state of engineering structures, Autodesk Navisworks was used with the built-in Verity plugin. It provides joint usage of design data of various formats, made in AutoCAD and Revit products, as well as geometric objects and information received from geodetic devices of the building monitoring system.

\section{THE MAIN PART}

The essence of BIM-design and BIM-geodesy boils down to the fact that there is created a computer model of a new building. It carries all the information in reference to a new object. This kind of design involves, first of all, the collection and complex processing in the design process of all architectural, design, technological and production information about the object. The concept of BIM design and BIM geodesy implies that the entire building and everything related to it is considered as a single object.

The difficulty of passage from traditional design to digital one is that different experts approach the concept of BIM design and BIM geodesy in different ways. For some (project designers) BIM is a model and a product, for others (geodesists) BIM is a process of modeling and practical implementation of the survey process.

In any approach, a building information model (BIM) will meet the following criteria:

- $\quad$ consistency and correlation;

- $\quad$ spatial certainty;

- $\quad$ suitability for computer use;

- flexibility for model updates.

Digital information of the BIM model can be used for:

- architectural decisions (the model makes it possible to make informed decisions, increase the service life of buildings, improve efficiency in a team, create the visualization of not only the exterior, but also the interior of the structure);

- $\quad$ infrastructure design (the method makes it possible to locate correctly terrain objects and ensure the reliability of structures);

- design of linear objects (the technique enables to visualize, design, detail and manufacture engineering communications of a complex configuration).

- construction of engineering structures (BIM-model in combination with geodetic measurements allows creating a digital copy of the area and making informed decisions);

- $\quad$ geodetic monitoring of engineering structures (BIMgeodetic model enables to identify the deformations of a particular structure quickly and accurately, identify hazardous areas in buildings and prevent possible emergencies).

In addition to all mentioned above, a BIM geodetic project can be also considered in time within the life cycle of an object. It is possible " to wear out" the future model or to predict its further functioning in relation to general urban development and, thereby, create a virtual copy of the building, which will fully correspond to the actual state of the object. Thus, digital information model can be defined as an object-oriented parametric three-dimensional model that digitally represents physical, functional and other characteristics of an object (or its individual parts) in the form of a set of information elements.

At the same time, the digital information model BIM plays an important role in the information management process. To implement a complete technological BIM-modeling and information management of the process of creating one or another engineering structure at all stages of this process, there is a necessity of the information on the spatial data of structural elements obtained by using geodetic measuring instruments. The results of geodetic measurements are necessary both at the stage of creating an information model (designing), and at the stage of construction management using a digital model, and while monitoring during the operation of an object by prompt identifying of deformations and damage to building structures.

The work with BIM geodetic model is of continuous character, since it can have an unlimited number of clarifications and improvements. A BIM geodetic project can be used by operating organizations of any level, as well as to create $3 \mathrm{D}$ 
models of cities and 3D cadastre. The work with a BIM geodetic project will be carried out using the Internet and special software.

Nowadays in Ukraine, a significant part of the work related to geodetic support of construction is carried out by ordinary people and ordinary instruments according to paper drawings. And quite often we face the problem of not having direct agreement between the designer and the builder in online mode. There is no relationship in the overall chain of construction operations. And in order to fill the missing links in the overall chain, in the field of geodetic support of construction, Autodesk software products began to be widely used in the sphere of BIM design. Due to the widespread introduction of BIM technologies in construction operations, geodetic control of building structures can be carried out by one expert. The use of the information model obtained in the process of BIM design and BIM geodesy can significantly facilitate further work with the object. This engineering solution enables to bring together virtually all separate projects and elements of the entire structure. All the necessary nodes will be visible and easily accessible. BIM project of high quality enables to check the building for operational suitability in advance.

All the solutions of a BIM geodetic project are scalable and vectorial and it is enough to use the minimum level of integration, which consists of an Autodesk application and the simplest geodetic instrument, for example, any electronic total station. It is necessary to perform geodetic support of construction with high quality and with sufficient reliability. With this sort of technological chain, we divide the process of creating a BIM-geodetic model of an engineering structure into six stages:

1. Preparative analysis of the project. At this stage, we analyze the tasks in hand, study the features of the terrain and materials of past years, negotiate with the customer, analyze the scope of research and terms, calculate the cost of services and sign an agreement.

2. Model preparation. We need to prepare a model in a computer-aided design system. The model is prepared in the Revit application. The model must be bound to the coordinates that are used at the construction site. In this model it is also necessary to insert the points with which we will work at the fourth stage of the construction object survey. The results of this stage serve as the initial data for the work of project designers and the creation of a 3D model. We measure the building area, study the relief features, identify the horizontal and vertical coordinates of existing engineering networks, plantings, buildings and structures. We try to get as much information about the land plot as possible so that the designers wouldn't have any difficulties in further modeling.

3. Data conversion. It is an interchange data format. There is made a plain text format and the wireframe model is saved in the DWG format. Then we load this file into the field measuring instrument.

4. Survey stage. At this stage we carry out directly geodetic measurements of building structures or geodetic preparation of the area. This can be the setting out of the main axes of the building, the staking out of the points of the geodetic base, the control of deformations and displacements of building structures, the scanning of the object, etc. At this stage, we collect the amount of information and fill the BIM model with special characteristics, which we will further process and analyze.

5. Registration. We combine the obtained clouds with the point into a single data store. We carry out the adjustment and bind to the construction coordinate system.

6. Analysis of the BIM model. This is a huge stage of software processing and intellectual work, which is carried out by means of BIM programming. It is aimed at developing final conclusions on the actual state of an engineering structure at a given time and at prompt decision-making on the further operation of a structure or a separate construction.

The work according to this technology takes place in a single information environment. The model is transferred to the cloud storage. And the model is transferred to the BIM-360 LAYOUT field application from the storage. Then the work is carried out directly at the construction site. Geodesists save the measurement results in the tablet. As soon as the work is completed, the tablet is synchronized with the cloud storage. And after that, the data becomes available to all the users of the BIM model. At the final stage there is carried out the monitoring of structural deformations and there is made out a report.

Deformations of engineering structures can be caused by the external processes, natural phenomena and factors in relation to engineering structures, as well as by the impact of technogenic processes arising from human activities through the use of technical means and technologies. One of the main reasons for the increase in natural impacts is the increase of anthropogenic impact on the natural environment, including the placement of engineering facilities without the consideration of natural hazards; underdevelopment and low efficiency of systems for monitoring the environment and deformation processes of engineering structures.

Due to the reconstruction and new construction of a complex of office buildings on Dmitrievskaya street in Kiev, Ukraine, which are part of the architectural monuments of the Lukyanovskaya line, there was a need for geodetic support of construction and monitoring of deformations of a 4-storey frame office building (Figure 1). In order to solve this problem, the Kiev National University of Construction and Architecture developed a concept and introduced a system for monitoring deformations of frame buildings at the stage of construction of the office building.

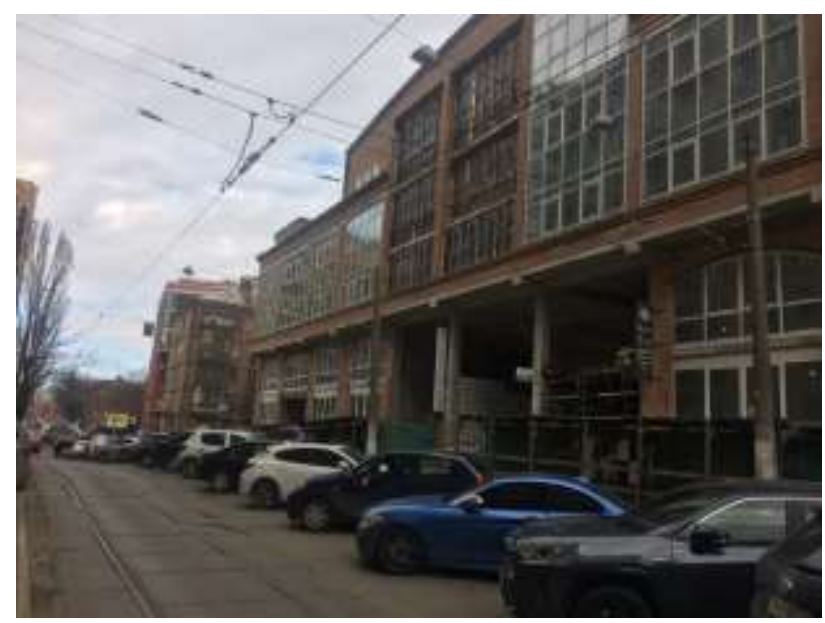

Figure 1. The office building on Dmitrievskaya street in Kiev. 
The execution of reconstruction and construction works below the level of the existing foundation of buildings and the Green Line of the metro, passing next to the construction area at a depth of 15 meters, did not guarantee complete immobility of the soils, foundations of buildings and structures. There was installed a hardware and software complex of the monitoring system in order to organize instrumental observations of building deformations in remote mode. The complex consisted of highly-accurate total stations, prisms and film reflectors, a laser scanner, tablets and the Navisworks and Revit Autodesc software package (Figure 2) with the built-in Verity plugin.

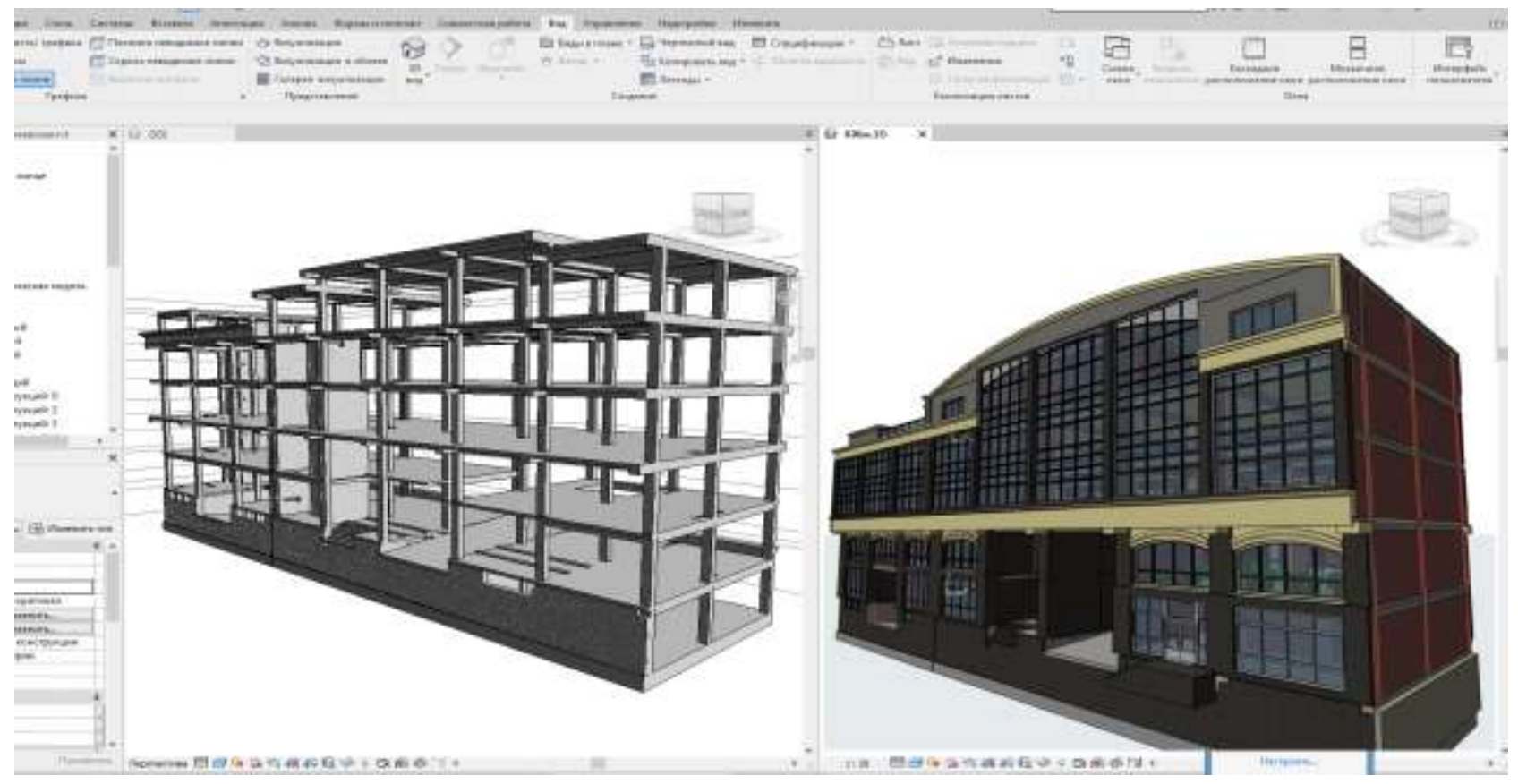

Figure 2. BIM model. Reinforced concrete frame and architectural fencing.

In order to balance the points of the geodetic basement, there was carried out periodically the position determination of the total stations by means of the resection method along the placed reference prisms on buildings which are located outside the deformation zone.

The use of heavy construction equipment with the vibrationimpact devices, as well as the violation of the foundations of all engineering structures of the complex, had a great impact on the existing buildings.

Electronic total stations were placed under protective glass caps, in order to provide the protection from the adverse weather conditions in the form of rain, snow, solar radiation and construction dust, and as a result, from pollution of the optical systems of the equipment. Operational control of deformations of the supporting structures of the frame building was carried out by using ground-based laser scanning.

At the stage of the model preparation, before going to the object, we receive a catalog of points with coordinates. We also analyze additionally the layout of the structure axes scheme and compare it with the layout scheme of the points of the geodetic construction network. This must be done for the cloud with the points to be correctly superimposed on this model at the stage of BIM model analysis. This must be done at the stage of BIM model analysis for the point cloud to be correctly placed on this model.

The scanning of structures with stationary scanners was carried out from several positions of the scanner by sequential rearrangement. At the registration stage, the individual scans were linked to each other and equalized. In this case the highest and most stable accuracy is achieved with the use of special targets. These are special tags and reflectors. For the most qualitative analysis, in addition to registration, it is necessary to bind scans to the local coordinate system.

The work of the field scanning was carried out by sequential rearranging of the scanner in space in order to cover the socalled "Dead Zones". We would like to pay attention to the fact that in this case we used two tools- a GLs2000 laser scanner and an electronic total station.

Why exactly two tools? The problem is that in order to obtain the most accurate result and the most accurate analysis, the scan results of the object must be linked to the local coordinate system of the building. A very effective technology for assessing the stability of objects is periodic geodetic observations from stations fixed in advance. The result of which is determined by the spatial coordinates of deformation tags. The conclusion is based on the analysis of changes in coordinates over time. For the correct assessment, it is very important that the calculations are performed in a single local coordinate system for the entire structure. And for various reasons that is not always easy to guarantee. In fact, as a rule it is not quite realistic to identify the position of all the deformation tags fixed on the object from one point of the scanner or total station. Thus it is not always possible to create a network of this kind of stations. When using linking points, it is important that these points are in sufficient quantity and located in a well-defined way.

Therefore, with the help of GLs2000 for linking by tags, it is necessary to capture at least 2 stamps by the adjacent scan. In this case, the divergences will grow during the transition from scan to scan. Hence, we recommend using the electronic total stations for control measurement of scanned tags and for adjustment of the geodetic network, built according to scanner 
tags. This will allow us not only to collect the scanner into a single data set, but it will also allow us to bind the whole model to the local coordinate system (Figure 3). As mentioned above, the analysis stage of the BIM model is performed by using the Verity plugin.

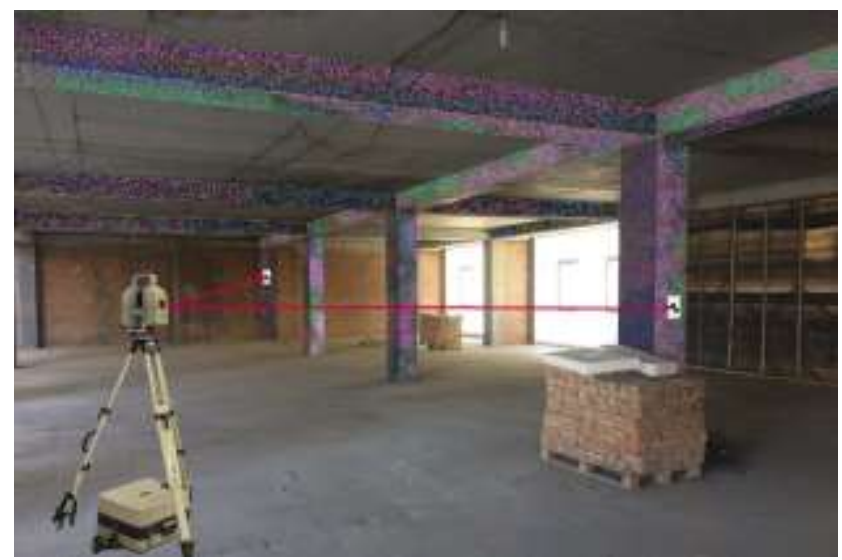

Figure 3. Spectral deformation zones of columns and floor beams

The model is loaded through the Navisworks interface. At the same time, many different formats are supported, including the Revit Autodesc format, the exchange format for IFC information models, and even the DWG format of the AutoCAD software package.
Then we load the cloud with the points, obtained from the results of geodetic laser surveying of building structures, into the processing program. The Autodesc ReCap format is used for the download. If the models and cloud with the points are linked to a local coordinate system, then mutual coordination is not required. If the data is not linked to a common system, then it is necessary to combine the model and the points cloud in a single coordinate basis using Navisworks tools.

The next step is to select structures for analysis of the deformation state and identify the deviations from the project. The selection of objects is carried out by means of Navisworks and allows selecting the structures of a certain category with certain properties. For instance, we select and group separately columns, pylons, walls, floor slabs, elevator shafts, staircases, etc. For all groups of objects of the same category, we set up maximum permissible deviations, as well as the accuracy of geodetic works. The given information is taken from the regulatory documentation for a particular type of construction activity.

At the analysis stage, we run the Verity plugin directly and it automatically identifies the model elements in the cloud points, identifies their actual position and calculates the deviation from the project. Then a certain "status" is assigned to the element that identifies the structure both "in tolerance" and "out of tolerance" (Figure 4). Depending on the "status", the element is painted in different colours, green or yellow.

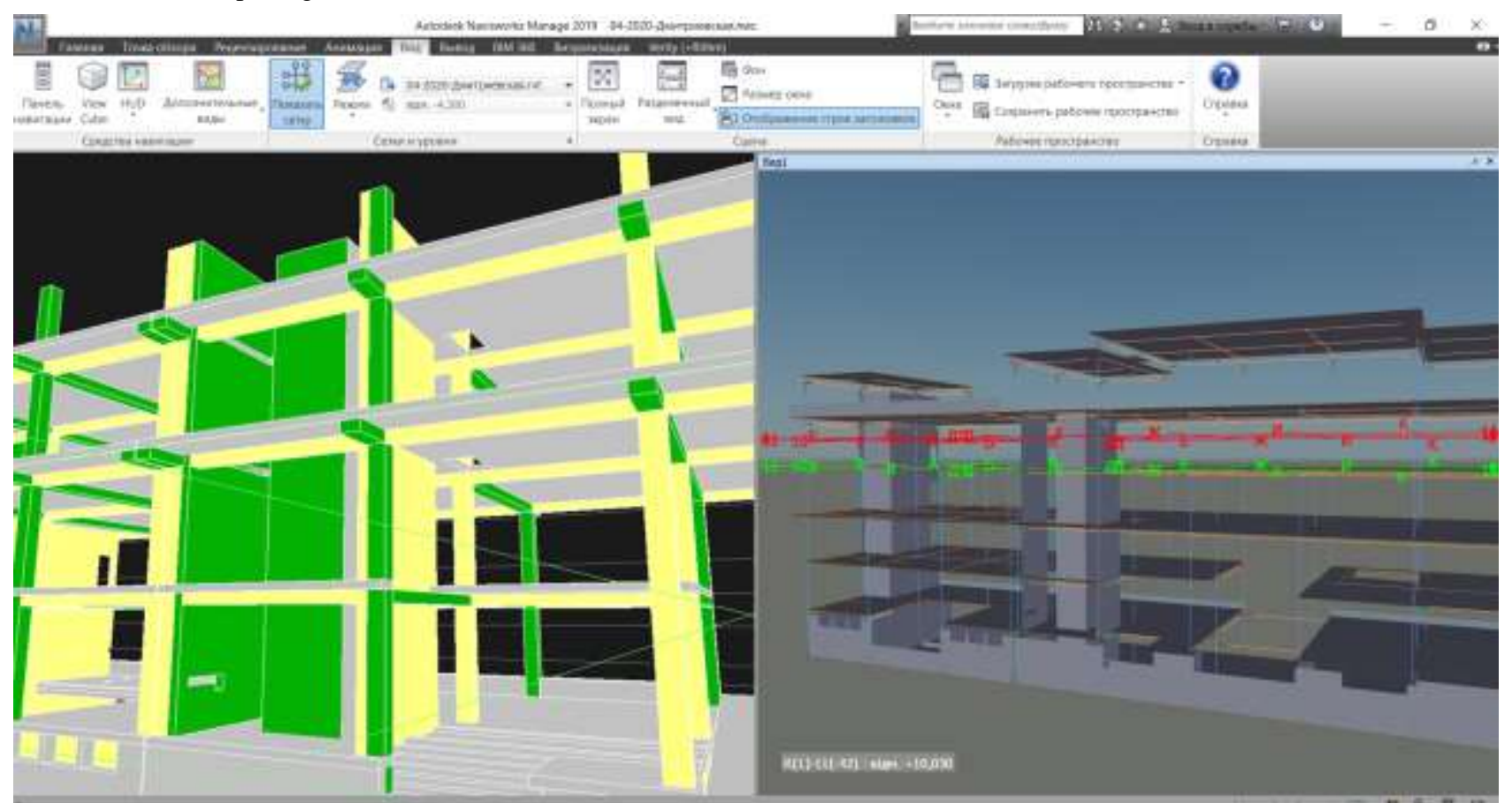

Figure 4. Structural deformation diagram.

At the analysis stage, the geodesist must check the correctness of the status setting for the objects and sign them to confirm the correctness of the final conclusion. In case the geodesist has any doubts, it is possible to start a recalculation for any separate structural element.

The final stage of geodetic monitoring of building structures using BIM technologies is the preparation of a report and the formation of conclusions for the further accident-free operation of a particular structure. For each object in the group of structures there is created a summary table. It is related to positional deviations in construction and to maximum permissible deviations. The structures themselves are painted with certain colors in order to make it visually comfortable to focus attention on deformations and damages. 
The report is made either in automatic mode with default settings or by the geodesist who can set independently the report form and characteristics of the displayed survey results. At each stage of construction, after the installation of the mounting level, geodesists update the BIM model of the building, taking into account the actual position of the structures at the time of monitoring. By combining the executive and design BIM models, there is carried out the analysis of the spatial and temporal arrangement of structures. After the analysis is completed, there is generated a report containing information of the actual and permissible deviations of structures in accordance with regulatory requirements.

The table contains information of the identified deviations during the period of construction and installation work of the office center.

\begin{tabular}{|l|c|c|c|}
\hline \multirow{2}{*}{$\begin{array}{c}\text { Name of the } \\
\text { structure }\end{array}$} & \multirow{2}{*}{\begin{tabular}{c} 
max, $\mathrm{mm}$ \\
\cline { 3 - 4 }
\end{tabular}} & \multicolumn{2}{|c|}{ Amount of structures } \\
\cline { 3 - 4 } & \pm 10 & 132 & $\begin{array}{c}\text { "out of } \\
\text { tolerance" }\end{array}$ \\
\hline columns & \pm 10 & 9 & 30 \\
\hline pylons & \pm 15 & 2 & - \\
\hline walls & \pm 5 & & 23 \\
\hline floor slabs & $1 / 400$ & 65 & 1 \\
\hline floor beams & \pm 10 & 4 & 6 \\
\hline elevator shafts & \pm 20 & 21 & 3 \\
\hline foundation & &
\end{tabular}

Table 1. Summary table of identified deviations during the construction period.

\section{CONCLUSIONS}

The results obtained during the project installation demonstrated the effectiveness of the use of BIM technologies for solving engineering problems in the geodetic support of the construction industry. The use of this technology enables to identify quickly and with sufficient accuracy deformations and deviations from the design of building structures that are caused by the impact of both external factors and the quality of construction. This technology makes it possible to detect project and construction errors at the early stages of construction and installation work. And in turn this improves the quality of the performed work.

It is also important to mention that the use of BIM technologies in the construction industry allows all participants in the design project, construction and operation of an engineering structure to provide quick access to engineering data about an object under construction. Whereas BIM geodetic model makes it possible to synchronize and adapt construction processes to the actual, spatial and temporal characteristics of structures.

This article presents the theoretical and practical results of the study of BIM-geodetic monitoring of deformations of building structures from external factors. The given work can be useful to each participant in the implementation of an engineering structure. Basing on the implemented projects, the article describes the main tasks that are solved by the BIM technology. There are presented the practical results of the combined application of laser scanning and of surveys with the use of the total stations at the stages of design, construction and operation of an engineering structure. There was described the technology of conducting geodetic monitoring using BIM technologies.

\section{REFERENCES}

Aziz D., Nawawi A. H., Ariff R. M. (2016). ICT Evolution in Facilities Management (FM): Building Information Modelling (BIM) as the Latest Technolog. Procedia - Social and Behavioral Sciences. Volume 234, 31 October 2016, pp. 363371. DOI: $10.1016 /$ j.sbspro.2016.10.253

Aziz D.,. Nawawi A. H, Ariff R.M. (2016) Building Information Modelling (BIM) in Facilities Management: Opportunities to be Considered by Facility Managers. Procedia - Social and Behavioral Sciences. 2016. - №. 234.- pp. 353362. DOI: $10.1016 /$ j.sbspro.2016.10.252

Bradley H., Lark R., Dunn S. (2016) BIM for infrastructure: An overall review and constructor perspective. Automation in Construction. 2016. - №. 71(2). - pp. 139-152. https://doi.org/10.1016/j.autcon.2016.08.019

Dinga L. Y., Zhonga B. T., Wub S., Luoa H. B. (2016) Construction risk knowledge management in BIM using ontology and semantic web technology. Safety Science V. 87, 2016, pp. 202-213. https://doi.org/10.1016/j.ssci.2016.04.008

Jee Woong Parka, Jingdao Chenb, Yong K. Choa (2017). Selfcorrective knowledge-based hybrid tracking system using BIM and multimodal sensors. Advanced Engineering Informatics, №. 32. pp. 126-138. https://doi.org/10.1016/j.aei.2017.02.001

Kang T. W., Hong C. H. (2015). A study on software architecture for effective BIM/GIS-based facility management data integration. Automation in Construction. - 2015. - №. 54. - pp. 25-38. https://doi.org/10.1016/j.autcon.2015.03.019

Panfilova E.E., Malkin I.I. (2020). Risk management information system in the organizations of the construction industry as a tool for increasing business revenue. Relevant lines of scientific research: theory and practice, 132-137. Cheboksary: SCC "Interaktiv plus", LLC. doi:10.21661/r530347

Sigalov K., Konig M. (2017). Recognition of process patterns for BIM-based construction schedules. Advanced Engineering Informatics. 2017 - №. 31. - $\quad$ pp. 45-48. https://doi.org/10.1016/j.aei.2016.12.003

Wetzel E.M., Thabet W.Y. (2015). The use of a BIM-based framework to support safe facility management processes. Automation in Construction. 2015. - №. 60. - pp. 12-24. https://doi.org/10.1016/j.autcon.2015.09.004

Zhang S., Teizer J., Lee J.-K., Eastman C. M., Venugopal M. (2013). Building Information Modeling (BIM) and Safety: Automatic Safety Checking of Construction Models and Schedules. Automation in Construction. - 2013. - Vol.29.- pp. 183-195. https://doi.org/10.1016/j.autcon.2012.05.006

Zoua Y., Kiviniemib A., Jonesa S.W. (2017). A review of risk management through BIM and BIM-related technologies. Safety Science, $2017 . \quad$ - №. 97.- pp. 88-98. https://doi.org/10.1016/j.ssci.2015.12.027 